\title{
O QUE ACONTECEU COM A SOCIEDADE DE LAZER? *
}

\author{
Jiri Zuzanek **
}

Resumo

Este texto apresenta a obra de Veal, A.J. (2019) Whatever Happened to the Leisure Society? London: Routledge, 296 p., expondo os estudos anteriores relacionados ao tema, realizando um balanço do campo e uma avaliação da obra em questão.

Palavras-chave: Lazer; História; Mudança Social; Sociedade.

\section{WHATEVER HAPPENED TO THE LEISURE SOCIETY?} \begin{abstract}
the previous studies on leisure field, makes a balance of the area and an assessment of the book reviewed.
\end{abstract}
This text presents the book Veal, A.J. (2019) Whatever Happened to the Leisure Society? London: Routledge, $296 \mathrm{p}$. It shows

Keywords: Leisure; History; Social Change; Society.

\section{¿QUÉ PASÓ CON LA SOCIEDAD DE OCIO?}

Este texto presenta el libro Veal, A.J. (2019) Whatever Happened to the Leisure Society? London: Routledge, 296 p., exponen los estúdios anteriores relacionado con el tema, realiza um balance del campo de estúdios y hace uma evaluación del libro bajo análisis.

Palabras clave: Ocio; Historia; Cambio Social; Sociedad.

Veal, A.J. (2019) Whatever Happened to the Leisure Society? London: Routledge, $296 \mathrm{p}$.

A noção de "sociedade do lazer" tornou-se parte do discurso intelectual na década de 1930. Coube a John Maynard Keynes formular na sua palestra Economic possibilities for our grandchildren (1930) uma visão da crescente quantidade de lazer, proporcionada pela mudança tecnológica - visão esta que influenciou muito do discurso subsequente sobre a "sociedade do lazer", incluindo as opiniões contraditórias de hoje sobre a mesma.

Em meados da década de 1960, a noção de uma "nova era de lazer estendido amplamente" tinha-se tornado, segundo Kenneth Galbraith (1967), numa "tema de convencional conversação". Os anos 60 foram um período de grandes esperanças no que diz respeito ao lazer. Fourastié (1965) previu que em 1985 os homens e mulheres franceses trabalhariam apenas um terço da sua vida, a duração da semana de trabalho não excederia 30 horas e seriam garantidas 12 semanas de férias. 0 influente livro de Dumazedier
Toward a Society of Leisure (1967) foi traduzido e publicado em inglês com uma introdução de David Riesman. Esperava-se que o 'Desenvolvimento de novos valores', 'valorização da auto-expressão', e 'revolução estética-ética', atribuídos ao lazer, enriquecessem a qualidade de vida (Society and Leisure, 1975/1). A ética do trabalho, segundo vários autores, devia dar lugar a um novo 'ethos do lazer' (Bosserman, 1977; Martin e Mason, 1985).

O otimismo em relação ao papel do lazer começou a desvanecer-se nas décadas de 1970 e 1980. Num ensaio polémico The Harried Leisure Class, Staffan Linder (1970) questionou a crença amplamente partilhada na abundância do lazer nas sociedades pósindustriais e sugeriu que as pessoas nestas sociedades levam vidas cada vez mais agitadas em vez de vidas de lazer. O interesse deslocou-se para os problemas da pressão do tempo em vez da abundância do lazer e, no final do milênio, a discussão sobre a chegada de uma "sociedade de lazer" foi relegada, com algumas excepções, para o jornalismo casual em vez de uma investigação social séria.

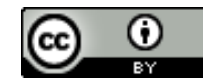

Licenciada por Creative Commons 4.0 / Internacional CC BY 4.0
* Texto traduzido, com a permissão do autor, por Inácio Botto Ferreira e Thiago Duarte Pimentel. Revisão técnica: Thiago Duarte Pimentel.

${ }^{* *} \mathrm{PhD}$ in Sociology (1970), Charles University, Prague, Czech Republic. Distinguished Professor Emeritus at the University of Waterloo, Canada. Formerly held appointments in the University of Lund, Sweden, Queens College in New York, and the University of Western Ontario, Canada. Was Research Director of the UNESCO European Centre for Leisure and Education, Prague. Subjects of interest: areas: leisure, labor, human identity, social change, social integration, stratification, division of labor, well-being, society of leisure. Address: University of Waterloo, 200 University Ave W, Waterloo, ON N2L 3G1, Canadá [zuzanek@uwaterloo.ca]. 
$O$ livro de A. J. Veal Whatever happened to the leisure society? é uma exceção. Se alguém quiser saber mais sobre a história e a validade da noção de 'sociedade de lazer', a publicação de Veal é peça obrigatória. Seu livro fornece uma descrição notavelmente detalhada e precisa das posições tomadas relativamente à "sociedade do lazer" por diferentes autores, desde a década de 1930 até aos nossos dias. Não contei o número preciso de autores, cujas opiniões sobre a "sociedade do lazer" são comentadas no livro de Veal, mas há bem mais de uma centena. Embora o conceito de sociedade do lazer estivesse sempre no centro do meu interesse, devo confessar que a publicação chamou a minha atenção para um certo número de autores, cujas contribuições ignorei.

A publicação tem duas partes principais: uma que trata da pré-história e história do conceito de "sociedade do lazer" e a outra com as análises da validade deste conceito. Pessoalmente, achei a parte histórica particularmente interessante. Nela, Veal resume de forma suscinta e objetiva e as posições de autores-chave, que contribuíram para o discurso sobre a sociedade do lazer antes de 1939, entre 1945 e 1959, e durante o período de crescente cepticismo desde os anos 60 até ao novo milênio.

Aqui estão alguns dos nomes para estes períodos: Alfred Lloyd, Bertrand Russell, George Cutten, Jay Nash, John Maynard Keynes, George Lundberg, Lewis Mumford, Henry Durant, para 0 período de 1920 a 1939; Georges Friedmann, David Riesman, Jacques Ellul, Herbert Marcuse, Erich Fromm, Henry Swados, para o período de 1945 a 1959; Daniel Bell, Herman Kahn, Alain Touraine, Clark Kerrr, Max Kaplan, Joffre Dumazedier, Kenneth Roberts, John Neulinger, John Kenneth Galbraith, Stanley Parker, Dennis Gabor, Andre Gorz, Staffan Linder, Jeremy Rifkin, Jonathan Gershuny, Juliet Schor, Chris Rojek para o fim do século XX e o início do século XXI.

As análises da validade do "cenário de lazer" centram-se nas questões de se ele se materializou e se não, como parece ser o caso, e por que não.

A conclusão de Veal - baseada em evidências acerca de uso do tempo - é que a adoção do termo "sociedade do lazer" nos anos sessenta foi infeliz. Esta noção implicava uma "sociedade sem trabalho", que era "claramente uma fantasia ou uma distopia" ( $p$. 286). 0 conceito de sociedade de lazer continha elementos de 'verdade', mas "não se baseava numa leitura extensa e cuidadosa e na ponderação das provas disponíveis" (p. 277).

A resposta de Veal à questão, de porquê é que 0 cenário da sociedade de lazer não se materializou, é relativamente concisa e o seu fracasso é atribuído, em parte, à mudança da economia para as indústrias de serviços, onde as horas de trabalho continuaram a ser longas, e ao facto de "o dividendo do aumento da produtividade nos países economicamente desenvolvidos ter ido para o capital em vez do trabalho (p. 279). Nos últimos capítulos do livro, Veal aborda as importantes questões da relação trabalho-lazer e da luta pelo tempo, cujo interesse tem, lamentavelmente, diminuído entre os investigadores de lazer.

Uma questão à parte no que diz respeito à sociedade do lazer, levantada por Veal, centra-se na distinção entre os conceitos de "sociedade do lazer" e "civilização do lazer", como refletido nos escritos de Joffre Dumazedier. A visão de Dumazedier sobre a "civilização do lazer" baseou-se, de fato, não numa crença de eliminação ou redução radical do trabalho, mas numa mudança de valores sociais, na qual o lazer foi considerado importante como fonte de maior qualidade de vida humana.

Dumazedier era um investigador, mas, como muitos membros da sua geração - marcados pela trágica experiência da Primeira Guerra Mundial em que o seu pai caiu na batalha de Verdun - ele também foi um reformador social. Veal não responde à questão de saber se a esperança de Dumazedier em relação ao papel potencialmente edificante do lazer, no contexto da "civilização do lazer", se materializou no nosso tempo, mas reconhece ter tomado consciência da sua importância no final dos anos 80 (p. 166).

Simpatizo com a visão de Dumazedier, mas receio que - se ela se materializou - então não aconteceu na forma "reformista" esperada. Infelizmente, como observado há algum tempo por Lazarsfeld e Merton, os meios de comunicação social parecem ter enganado os reformadores dos frutos das suas vitórias. Mesmo os cidadãos, que ganharam tempo livre adicional, não 0 aproveitaram necessariamente em usos equilibrados, previstos no conceito de "civilização do lazer".

Contudo, como sabemos, a realidade e a esperança são duas coisas diferentes. Embora admitindo que o conceito de 'sociedade do lazer' não se materializou, citações de Veal cita com simpatia o apelo de Anthony Giddens para um ' apelam ao 'realismo utópico' da criação de um mundo melhor, onde 0 lazer poderia desempenhar um papel importante. Mesmo que a 'sociedade do lazer' fosse uma fantasia, o lazer e o seu papel certamente não 0 são, e é convicção de Veal que a reforma social pode ajudar o lazer a contribuir para uma maior qualidade de vida e estilos de vida mais equilibrados. Para que tal reforma seja bem sucedida, os investigadores têm, contudo, de passar do pensamento abstrato para processos e arenas "em que tal desenvolvimento tem hipóteses de se concretizar" (p. 286). 
O meu comentário final nesta resenha é dirigido àqueles que tentarão, no futuro, dizer algo de novo sobre o conceito de "sociedade do lazer". Por favor, leia primeiro apenas o livro de Tony Veal. Talvez ele já o tenha dito.

\section{REFERÊNCIAS}

Bosserman, P. (1974). The Making of a Leisure Ethic. Paper Presented at Université du Québec à Trois-Rivières.

Dumazedier, J. (1967). Toward a Society of Leisure. Glencoe: The Free Press.

Fourastié, J. (1965). Les 40,000 Heures. Paris: LaffontGonthier.

Galbraith, J. K. (1967). The New Industrial State. New York: Signet Books.

Giddens, A. (1990). Modernity and utopia. New Statesman and Society.
Keynes, J. M. (1963/1930). Essays in persuasion. New York: W.W. Norton \& Co.

Lazarsfeld, P. F. and Merton, R. K. (1957), Mass Communication, Popular Taste and Organized Social Action. In: Rosenberg, B. and D. M. White (Eds.), Mass Culture, The Popular Arts in America. London: The Free Press of Glencoe.

Linder, S.B. (1970). The Harried Leisure Class. New York: Columbia University Press.

Lundberg, G., M. Komarovsky, and M. Mclnery (1934). Leisure: A Suburban Study. New York: Columbia University Press.

Martin, W.H. and S. Mason. (1985). The development of a leisure ethic: some practical issues for the future. In: $\mathrm{S}$. Parker and A.J. Veal (Eds.), Work, Non-Work and Leisure. LSA Publication 23. Eastbourne: Leisure Studies Association.

Processo Editorial / Editorial Process / Proceso Editorial

Editor Chefe / Editor-in-chief / Editor Jefe: PhD Thiago D. Pimentel (UFJF).

Recebido / Received / Recibido: 25.11.2020; Revisado / Revised / Revisado: 07.12.2020; Aprovado / Approved / Aprobado: 10.12. 2020; Publicado / Published / Publicado (online): 13.10.2020.

Tradução do original ao autor / Translation of author's original paper / Texto traducido de la versión original del autor.

Seção não revisada às cegas por pares / No double blind review section / Sessión no revisada por pares ciegos. 